\title{
Emphysema in a non-industrialized tropical island
}

\author{
J OH N A. HAYES ${ }^{1}$ A ND JOAN M. SUMMERELL \\ From the Pathology Department, University of the West Indies, Mona, Kingston 7, Jamaica
}

\begin{abstract}
Whole lung sections (Gough-Wentworth) have been prepared after formalin liquid distension of the lungs from 643 necropsies performed in Jamaica. These included 572 Negro (African), 18 East Indian, 25 Chinese, and 28 white cases. Emphysematous change was assessed visually by comparison with a standard set of sections from Cardiff which were similar to those adopted by the Ciba Guest Symposium in 1959. Severe destructive emphysema was present in $1.8 \%$ of males and in $1.0 \%$ of females. Emphysema was more severe, and more frequent, in males than in females, while both sexes showed an increasing frequency and severity with advancing years. No appreciable racial difference was seen, except that 'focal' emphysema, which includes the centrilobular type, was somewhat more frequent in East Indians than in the other racial groups. These observations indicate the occurrence of emphysema of the more common types in a hot climate which is apparently free of atmospheric pollution.
\end{abstract}

In recent years there has been renewed interest in chronic lung disease, largely due to the development of newer techniques for assessing physiological and morphological damage to the lung. Current concepts of the aetiology of these conditions, particularly chronic bronchitis and emphysema, have stressed the influence of cold, damp climates with atmospheric pollution by cigarette smoking, heavy industry, and urbanization. Implicit in these ideas has been the assumption that emphysema and chronic bronchitis do not occur in tropical countries because they do not have a damp, industrially polluted atmosphere. The finding of a significant amount of emphysema in Jamaica, which is a tropical island with no heavy industry, questions this assumption. This paper, which is an extension of a previous study (Hayes and Summerell, 1963), presents postmortem observations on emphysema made over a four-year period in Jamaica, together with a brief discussion of the significance of these findings.

\section{MATERIALS AND METHODS}

Whole lung sections were prepared from lungs obtained at routine necropsies in the Pathology Department of the University Hospital of the West Indies, the left lung being used in most cases. The cases studied were adults, of both sexes, aged 17 years and older. There was no selection of cases, and the only cases excluded were those in which the lungs were badly damaged accidentally or during medico-

1Present address: Mallory Institute of Pathology, Boston City Hospital, Boston, Mass. 02118 legal examination. In effect the cases formed a consecutive, unselected group of necropsies.

The lungs were fixed by distension with $10 \%$ formol-acetate at a pressure of $30 \mathrm{~cm}$. of water. After fixation whole lung sections were cut by the method described by Gough and Wentworth (1960). The paper-mounted sections were graded for severity of emphysema by comparison with standard sections supplied by Professor J. Gough. Each section was divided into six zones (Fig. 1) and each zone was assessed by area of emphysematous involvement in

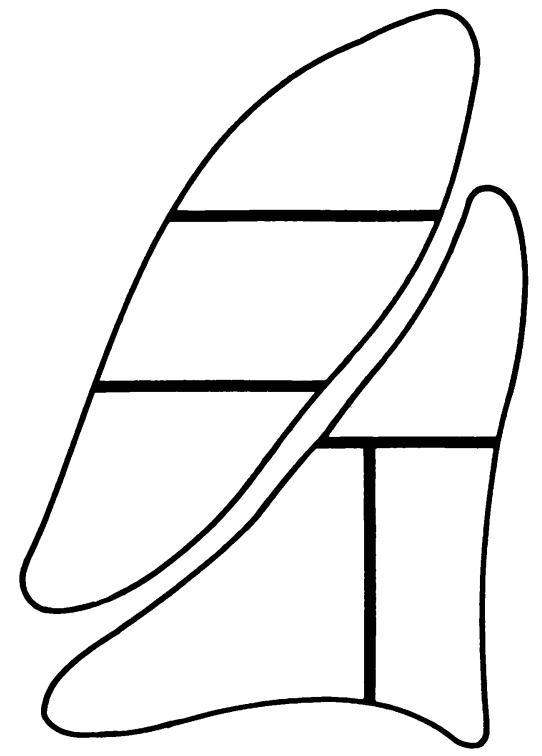

FIG. 1. Diagram showing the six sectors assessed for emphysema in each paper section of lung. 
T A B L E

EMPHYSEMA IN RELATION TO AGE AND SEX ${ }^{1}$

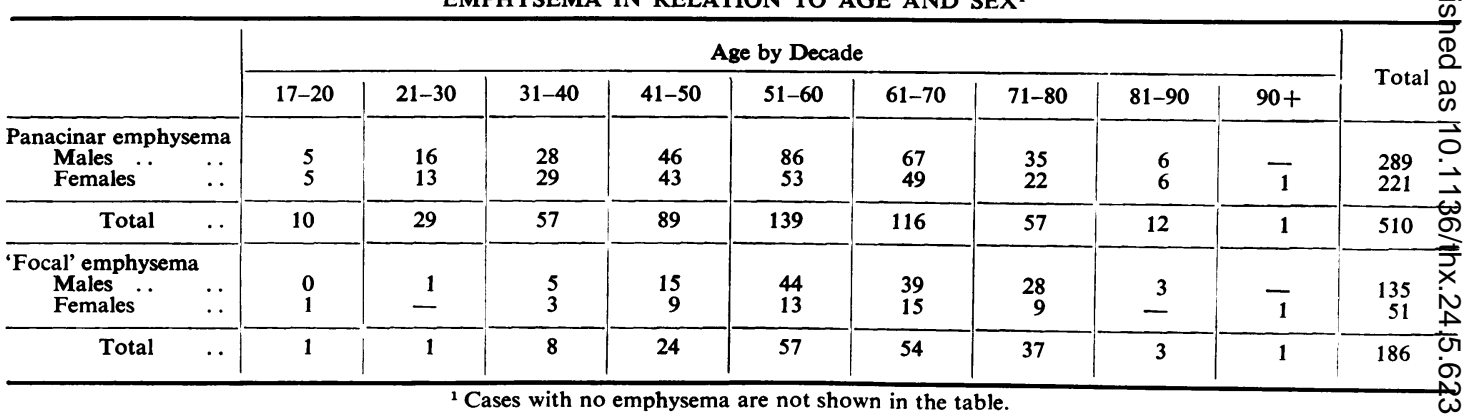

grades varying from 0 to 3 ( 0 represented no emphysema and 3, severe, extensive emphysema). The score from each of the six zones was combined to give an emphysema score of between 0 and 18 for each section (Heard and Izukawa, 1964). Separate assessments were made for panacinar (panlobular) and for 'focal' emphysema on each section. The term 'focal' is used because it was not practicable, in the large number of cases examined, to distinguish between centrilobular emphysema (Leopold and Gough, 1957) and true, focal, dust pneumoconiosis (Heppleston, 1953), without using serial histological sections. The majority of these lesions, however, were of the centrilobular type.

Two observers examined the entire group of paper sections independently and assigned scores to each after referring to the standard sections. The results were compared, and in cases with differing scores the sections were re-examined and a final value was assigned after discussion between observers. The values obtained were transferred to punch cards and analysed with respect to age, sex, type, and severity of emphysema.

\section{RESULTS}

Between 20 March 1962 and 28 October 1965 some 1,600 necropsies were performed in the Pathology Department of the University of the West Indies. Nine hundred and sixty examinations were on adults of both sexes, aged 17 years and over. Whole lung sections were available from 643 adult cases, in which the racial distribution was African-Negro 572, East Indian 18, Chinese 25 , and white 28 cases respectively. These groups are broad approximations due to the extensive intermarriage between the different racial groups. The distribution of both forms of emphysema by severity in each sex is shown in Figs 2 and 3. The Table shows the distribution of each form of emphysema by age.

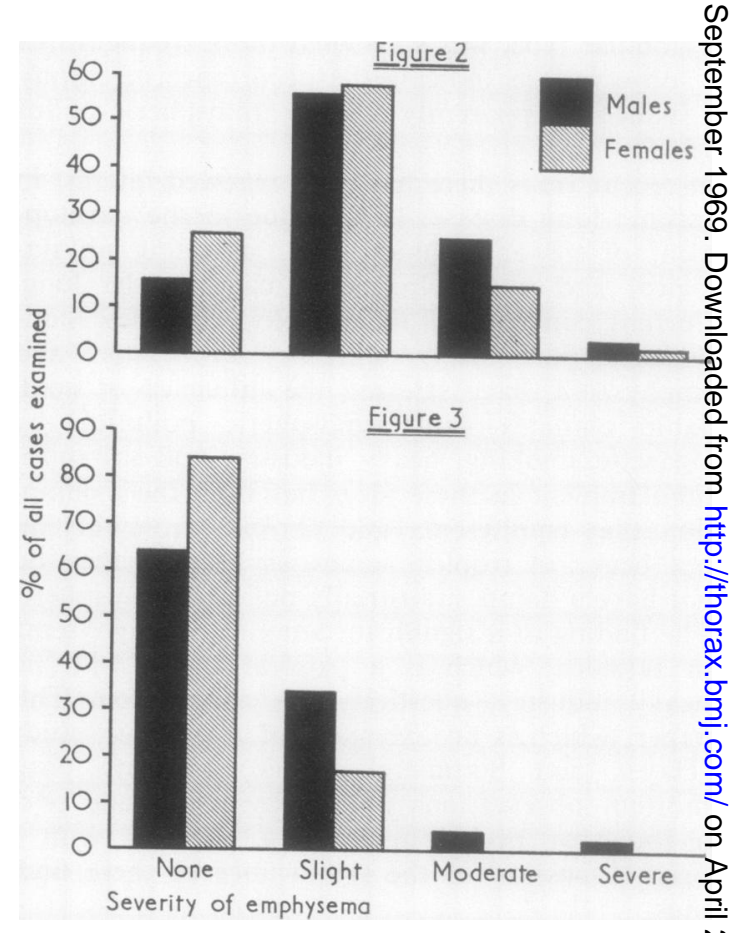

FIG. 2. Distribution of panacinar emphysema by severity in males and females.

FIG. 3. Distribution of 'focal' emphysema by severity i males and females.

\section{DISCUSSION}

Although the emphysematous change in the cases -0 studied may possibly not be as severe, the frequency of the anatomical changes is very similar? to that reported from Europe and North America. $\stackrel{\mathbb{Q}}{2}$ It would be unwise to be more definite, because there is no strictly comparable study from a tem- 
perate climate zone, except possibly that by Thurlbeck in Boston (Thurlbeck, 1963). Thurlbeck showed that severe, destructive emphysema occurred in $6.5 \%$ of 138 cases. The figure obtained in the present study is $1.8 \%$ in males and $1.0 \%$ in females based on 643 cases. This comparison may be questioned on two grounds. Firstly, the methods of preparation were different. Secondly, it is doubtful whether the admissions to the Massachusetts General Hospital are as representative of the general population of Boston as the admissions to the University Hospital of the West Indies are representative of the Jamaican population.

Although these objections are important, they are not really pertinent. This study shows that emphysema of the commonly recognized types occurs in the indigenous population of Jamaica ; that the changes occur with greater frequency and are more severe in males than in females; and that the changes in both sexes increase with age. This finding is unexpected, because emphysema is commonly associated with cold, damp climates where there is abundant atmospheric pollution.

Atmospheric pollution, as experienced in the industrialized areas of Britain, certainly does not exist in Jamaica, as industry is of recent origin and the number of automobiles has increased only lately. If there is atmospheric pollution it is not likely to be of the conventional kind. Although severe lung damage, particularly at the bronchiolar level, has been demonstrated during severe influenza epidemics (Hers and Mulder, 1953; Stuart-Harris, 1965), damage to the smaller airways has not been related to the less severe forms of viral respiratory infection of the types identified by Jennings in Jamaica (Jennings, 1967 ; Jennings and Grant, 1967a, b). Although not necessarily a sequel of respiratory tract infection, typical chronic bronchitis with a chronic productive cough is encountered in hospital practice in Jamaica (Miller and Hayes, 1968). Much of this is undoubtedly associated with cigarette smoking (Walshe and Hayes, 1967), although it is not possible to say with confidence that this is the major aetiological factor involved. Clinical studies have shown that chronic bronchitis (Massaro, Cusick, and Katz, 1965) and emphysema (Murphy, Katz, Massaro, and Luchsinger, 1962) are less common in Negro than in white ex-Servicemen in the United States. The bulk of the cases studied here were Negro and there was no apparent racial difference for panacinar emphysema. With 'focal' emphysema there was a suggestion that East Indians were affected with greater frequency than the other racial groups.

As this was a necropsy study firm conclusions cannot be drawn due to possible factors affecting selection. However, it is safe to say that the presence of emphysema in the absence of the usual forms of atmospheric pollution is noteworthy.

\section{REFERENCES}

Ciba Guest Symposium (1959). Terminology, definitions, and classification of chronic emphysema and related conditions. Thorax, $14,286$.

Gough, J., and Wentworth, J. E. (1960). Thin sections of entire organs mounted on paper. In Recent Advances in Pathology. Ed., Harrison, C. V., pp. 80-86, 7th ed., Churchill, London.

Hayes, J. A., and Summerell, J. (1963). Emphysema in Jamaica. $W$. Indian med. J., 12, 34 .

Heard, B. E., and Izukawa, T. (1964). Pulmonary emphysema in fifty consecutive male necropsies in London. J. Path. Bact., 88, 423.

Heppleston, A. G. (1953). The pathological anatomy of simple pneumokoniosis in coal workers. Ibid., 66, 235.

Hers, J. F. P., and Mulder, J. (1953). The mucosal epithelium of the respiratory tract in muco-purulent bronchitis caused by Haemophilus influenzae. J. Path. Bact., 66, 103.

Jennings, R. (1967). The role of respiratory viruses in Jamaica. Ph.D. Thesis, University of the West Indies.

and Grant, L. S. (1967a). Respiratory viruses in Jamaica: a virologic and serologic study. I. Virus isolations and serologic studies on clinical specimens. Amer. J. Epidem., 86, 690.

_ (1967b). Respiratory viruses in Jamaica: a virologic and serologic study. II. Hemagglutination-inhibiting antibodies to influenza $A$ viruses in the sera of Jamaicans. Ibid., 86, 700.

Leopold, J. G., and Gough, J. (1957). The centrilobular form of hypertrophic emphysema and its relation to chronic bronchitis. Thorax, 12, 219.

Massaro, D., Cusick, A., and Katz, S. (1965). Racial differences in incidence of chronic bronchitis. Amer. Rev. resp. Dis., 92, 94.

Miller, G., and Hayes, J. A. (1968). Unpublished data.

Murphy, R. E., Katz, S., Massaro, D. J., and Luchsinger, P. C. (1962). Is emphysema a disease predominantly of the white male? J. Amer. med. Ass., 181, 726.

Stuart-Harris, C. H. (1965). Influenza and Other Virus Infections of the Respiratory Tract, 2nd ed. Arnold, London.

Thurlbeck, W. M. (1963). The incidence of pulmonary emphysema: with observations on the relative incidence and special distribution of various types of emphysema. Amer. Rev. resp. Dis., 87, 206.

Walshe, M. M., and Hayes, J. A. (1967). Respiratory symptoms and smoking habits in Jamaica. Ibid., 96, 640. 